\title{
Dynamic Monitoring of the Water Flowing Fractured Zone during the Mining Process under a River
}

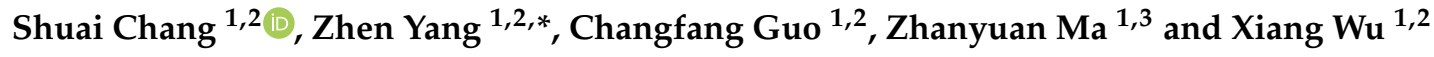 \\ 1 Key Laboratory of Deep Coal Resource Mining, Ministry of Education of China, School of Mines, \\ China University of Mining \& Technology, Xuzhou 221116, China; simonchang@cumt.edu.cn (S.C.); \\ guochangfang@cumt.edu.cn (C.G.); tm_mazhanyuan@163.com (Z.M.); lanran@cumt.edu.cn (X.W.) \\ 2 State Key Laboratory of Coal Resources and Safe Mining, China University of Mining and Technology, \\ Xuzhou 221116, China \\ 3 Datang Tashan Coal Mine Company Limited, Datong Coal Mine Group Company Limited, \\ Datong 037003, China \\ * Correspondence: yangzhen@cumt.edu.cn; Tel.: +86-18651798874
}

Received: 26 November 2018; Accepted: 19 December 2018; Published: 23 December 2018

\begin{abstract}
The hydrogeological conditions of coal mines in China are quite complex, and water inrush accidents occur frequently with disastrous consequences during coal extraction. Among them, the risk of coal mining under a river is the highest due to the high water transmissivity and lateral charge capacity of the unconfined aquifer under the river. The danger of mining under a river requires the accurate determination of the developmental mechanisms of the water flowing fractured zone (WFFZ) and the water flow mechanisms influenced by the specific geological conditions of a coal mine. This paper first used the transient electromagnetic (TEM) method to monitor the development of the WFFZ and the water flow mechanisms following the mining of a longwall face under a river. The TEM survey results showed that the middle Jurassic coarse sandstone aquifer and the $\mathrm{K}_{\mathrm{lzh}}$ unconfined aquifer were the main aquifers of the 8101 longwall panel, and the WFFZ reached the aquifers during the mining process. Due to the limited water reserves in the dry season, the downward flowing water mainly came from the lateral recharge in the aquifer. The water inrush mechanisms of the 8101 longwall panel in Selian No.1 Coal mine were analyzed based on the water flow mechanisms of the aquifer and the numerical simulation results. This provides theoretical and technical guidance to enact safety measures for mining beneath aquifers.
\end{abstract}

Keywords: monitoring; water flowing fractured zone; aquifer; water flow mechanisms; lateral recharge; transient electromagnetic method

\section{Introduction}

The hydrogeological conditions of coal mines in China are quite complex, and water-bearing bodies exist in coal mines. Water inrush accidents not only cause a huge number of casualties and economic losses but also seriously affect the normal production of the coal mine. Water inrush accidents occur mostly as roof water inrush during extraction. In general, the fractured roof strata can be divided into the caved zone, fractured zone and bending zone. The water flowing fractured zone (WFFZ) is composed of the lower two zones, in which mining-induced fractures are relatively developed. The connection between the mining-induced fractures of the longwall face and the overlying water-bearing bodies results in a strong water-conducting channel, through which the water from the overlying aquifer flows downward into the longwall face and causes a water inrush accident. Consequently, it is necessary to determine the developmental mechanisms of a WFFZ and the water flow mechanisms during the mining process to guide the safe extraction of a longwall face. 
Many scholars have studied the developmental mechanism and height prediction of WFFZs. An empirical formula was developed through both theoretical and practical research involving several hundred longwall faces in the development of a WFFZ of overlying rock strata after mining [1,2], providing a theoretical basis for the fast calculation of the height of a WFFZ. Miao et al. [3] studied the key stratum of the overlying strata and found the effects that the key stratum has on the development height of the WFFZ. Gao et al. [4] detected the height of the WFFZ after mining using a borehole water injection (discharge) fracture measuring system and a borehole teleview logging system. These measures turned out to be intuitive and precise. Currently, numerical simulation and laboratory modeling are used mostly to estimate the development of the WFFZ and water inrush mechanisms [5-8]. Field detection after mining is also widely used. However, no research on the measurement of the height of the WFFZ and water inrush mechanisms during the mining process has been reported. Because the transient electromagnetic (TEM) method is sensitive to low apparent resistivity areas, simple in construction and adaptable to complex geologic environments, it has been widely used to detect water enrichment areas in recent years [9-13]. The TEM method has been widely used due to its sensitivity to underground aquifers [14-16]. Xue et al. [10] used the TEM method to detect a mined-out area and concluded that the water-filled voids were enlarging with time. Rödder et al. [17] detected both sides of the Araba fault using the TEM method combined with 2D forward modeling, 3D forward modeling and data processing, and then analyzed the difference in resistivity on the two sides of the Araba fault. Therefore, this paper attempts to detect the WFFZ with the TEM method.

The present research was carried out in the Selian No. 1 coal mine. There is a river passing through the surface of the 8101 longwall face. The river is usually dry, and the main source of water is rain, which can cause a temporary flood. The mining depth in this area is approximately $125 \mathrm{~m}$. The unconfined aquifer beneath the river has strong lateral recharge capacity, and the groundwater reserves in the rainy season are extremely large. Once the flood water flows down the mining-induced fractures into the longwall face, it will cause a serious accident. The objective of the present research was to monitor the developmental mechanisms of the WFFZ following the mining of the longwall face and analyze the water inrush mechanisms of the 8101 longwall face. It is hoped that the results can provide technical support for mining beneath aquifers and provide a reference for future research on groundwater resource migration and environmental protection.

\section{Survey Area}

\subsection{Geological Conditions}

The Selian No. 1 coal mine lies in the Dongsheng District of Ordos, Inner Mongolia ( $39^{\circ} 53^{\prime} 52.85^{\prime \prime} \mathrm{N}$, $109^{\circ} 52^{\prime} 37.49^{\prime \prime}$ E). Characterized by a fluctuating surface, the terrain of this area is high in the north and low in the south (Figure 1). The gullies are widely developed in and around this area, and the rivers are seasonal. The recorded maximum flood peak of the around area is $2580 \mathrm{~m}^{3} / \mathrm{h}$. The 8101 longwall face is the first longwall face in this coal mine in which the $2-2^{1}$ coal seam is mined. The strike length and the inclined length of the 8101 longwall face are $1780 \mathrm{~m}$ and $280 \mathrm{~m}$, respectively. The ground elevation is $1382-1442 \mathrm{~m}$, and the floor elevation is $1250-1264 \mathrm{~m}$. The average depth is approximately $170 \mathrm{~m}$, and the thickness of the coal seam ranges from 2.5 to $5.0 \mathrm{~m}$, with an average of $4.0 \mathrm{~m}$. There is a river (dry at that time) passing through the surface of the 8101 longwall face, beneath which the buried depth of the $2-2^{1}$ coal seam is approximately $125 \mathrm{~m}$.

The overburden strata are shown in Figure 2. There are four main aquifers: the Quaternary loose pore phreatic aquifer with low-medium water abundance and strong permeability, the $\mathrm{K}_{\mathrm{lzh}}$ unconfined aquifer in the lower series of the Cretaceous with low-medium water abundance, the middle Jurassic clastic rock type aquifer with low water abundance and poor permeability, and the Yan'an formation clastic rock type confined aquifer of the middle-lower Jurassic with low water abundance. Therefore, the main aquifers that pose a threat to the extraction of the 8101 longwall face are the $\mathrm{K}_{\mathrm{lzh}}$ unconfined 
aquifer and the middle Jurassic coarse sandstone aquifer. The $\mathrm{K}_{\mathrm{lzh}}$ unconfined aquifer is closely related to the river and has strong transmissivity and storage capacity. The water level of the unconfined aquifer is greatly affected by climatic conditions and seasonal changes. The water level of this aquifer rises with the rainy spring and summer, and drops with the less rainy winter. Due to its high water transmissivity and lateral recharge capacity, the drop in water level in some areas will cause the water recharge from other areas of the aquifer. Therefore, in order to ensure the mining safety of 8101 longwall face, it is necessary to study the developmental mechanisms of the WFFZ.
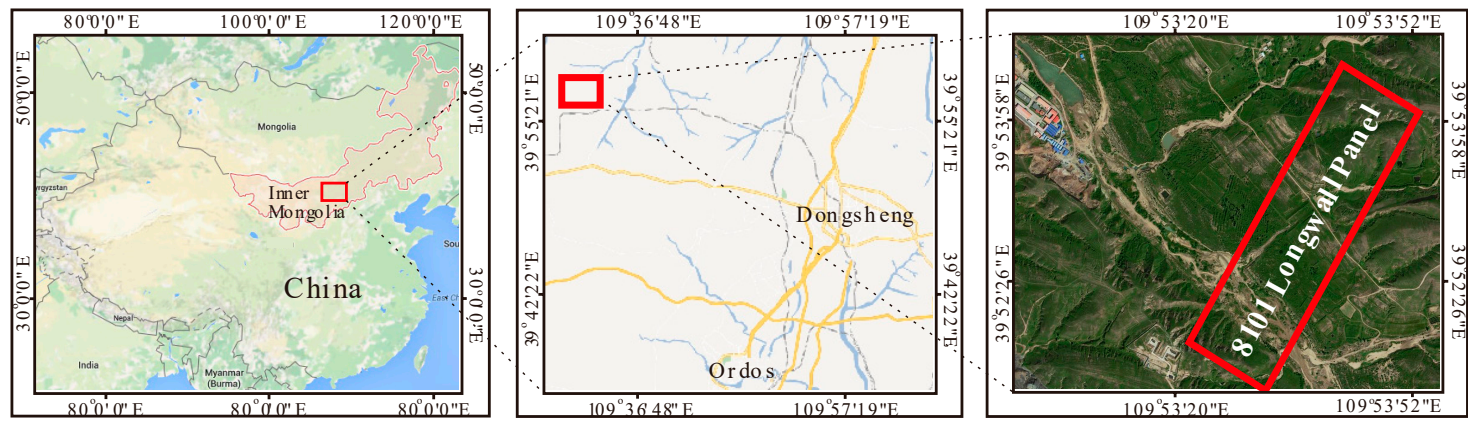

Figure 1. Location of the survey area.

\begin{tabular}{|c|c|c|c|c|c|}
\hline Age & Series & Formation & Symbol & Thicknes & Description \\
\hline Quaternary & Holocene & & & $9.53 \mathrm{~m}$ & $\begin{array}{l}\text { Wind-blown } \\
\text { Sand }\end{array}$ \\
\hline \multirow{2}{*}{ Cretaceous } & \multirow{2}{*}{$\begin{array}{l}\text { Lower } \\
\text { Series }\end{array}$} & \multirow[b]{2}{*}{$\mathrm{K}_{\text {lzh }}$} & $\overline{ } \cdot \overline{ }$ & \multirow{2}{*}{$7.97 \mathrm{~m}$} & \multirow{2}{*}{$\begin{array}{c}\text { Sandy } \\
\text { Mudstone \& } \\
\text { Sandstone }\end{array}$} \\
\hline & & & 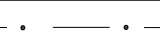 & & \\
\hline \multirow{16}{*}{ Jurassic } & \multirow{11}{*}{$\begin{array}{l}\text { Middle } \\
\text { Series }\end{array}$} & & $\begin{array}{lll}\cdot & \bullet & \bullet\end{array}$ & \multirow{2}{*}{$9.25 \mathrm{~m}$} & \multirow{2}{*}{$\begin{array}{c}\text { Coarse } \\
\text { Sandstone }\end{array}$} \\
\hline & & & - $\quad$ - & & \\
\hline & & & {$[\quad \cdot \bar{z}$} & \multirow{3}{*}{$30.66 \mathrm{~m}$} & \multirow{3}{*}{$\begin{array}{c}\text { Sandy } \\
\text { Mudstone }\end{array}$} \\
\hline & & & $-\cdot \square$ & & \\
\hline & & & 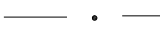 & & \\
\hline & & & . $\cdot$ - & & \\
\hline & & & $\cdot \cdot$ & $27.74 \mathrm{~m}$ & Sandstone \\
\hline & & & $\begin{array}{llllll} & \bullet & \bullet & \bullet\end{array}$ & & \\
\hline & & & $\square \cdot$ & & \\
\hline & & & $-\cdot \square$ & $31.90 \mathrm{~m}$ & $\begin{array}{l}\text { Sandy } \\
\text { Mudstone }\end{array}$ \\
\hline & & & {$[\quad$} & & \\
\hline & & & & $0.75 \mathrm{~m}$ & Coal Seam \\
\hline & & & •. $\quad \cdots \quad \cdots$ & & \\
\hline & Lower & Yan'an & - $\quad \cdots$ & $6.20 \mathrm{~m}$ & Siltstone \\
\hline & Middle & Formation & 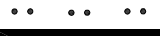 & & \\
\hline & Sentes & & & $3.30 \mathrm{~m}$ & $\begin{array}{c}\text { Coal } \\
\text { Seam } 2-2^{1}\end{array}$ \\
\hline
\end{tabular}

Figure 2. Geological log profile.

\subsection{Failure Characteristics of the Overburden Strata}

The three zones of the overlying strata are shown in Figure 3. The caved zone is located in the lowest part of the overlying strata. There is ample space between the rocks in this zone, which leads to strong connectivity. Water and sand can burst into the longwall panel through this tunnel. The fractured zone is located above the caving zone. Although the lithology changes little compared 
to the original strata, the fractures that generally exist in this zone promote the development of the water-conducting channel through which water can move downward to the goaf. The WFFZ is composed of the caved zone and the fractured zone. The bending zone refers to the strata between the top of the fractured zone and the surface. There are few fractures in this zone, and the water conductivity remains unchanged. Sometimes, the fractured zone can develop up to the surface when mining the shallow-buried longwall face. In this case, the overlying strata can be divided into two zones: the caved zone and the fractured zone.

During underground longwall mining, when the gob reaches a certain size, strata movement will reach the surface and form the subsidence basin. The scope of the subsidence area is larger than that of the gob. In other words, surface subsidence occurs in front of the longwall face under the influence of mining. The rock fractures of the overlying strata are developed in advance. This phenomenon is known as the advanced influence. Zone $\mathrm{A}$ is the fractured zone developed ahead of the working face, as illustrated in Figure 3. The advanced distance $(l)$ is defined as the horizontal distance between the working face and the point where the surface begins to move (with a surface subsidence of $10 \mathrm{~mm}$ ). The angle of advanced influence ( $\delta$, also known as the major influence angle) is related to the advanced distance and mining depth $(h)$, and their relationship is as follows [18]:

$$
\delta=\tan ^{-1} \frac{h}{l}
$$

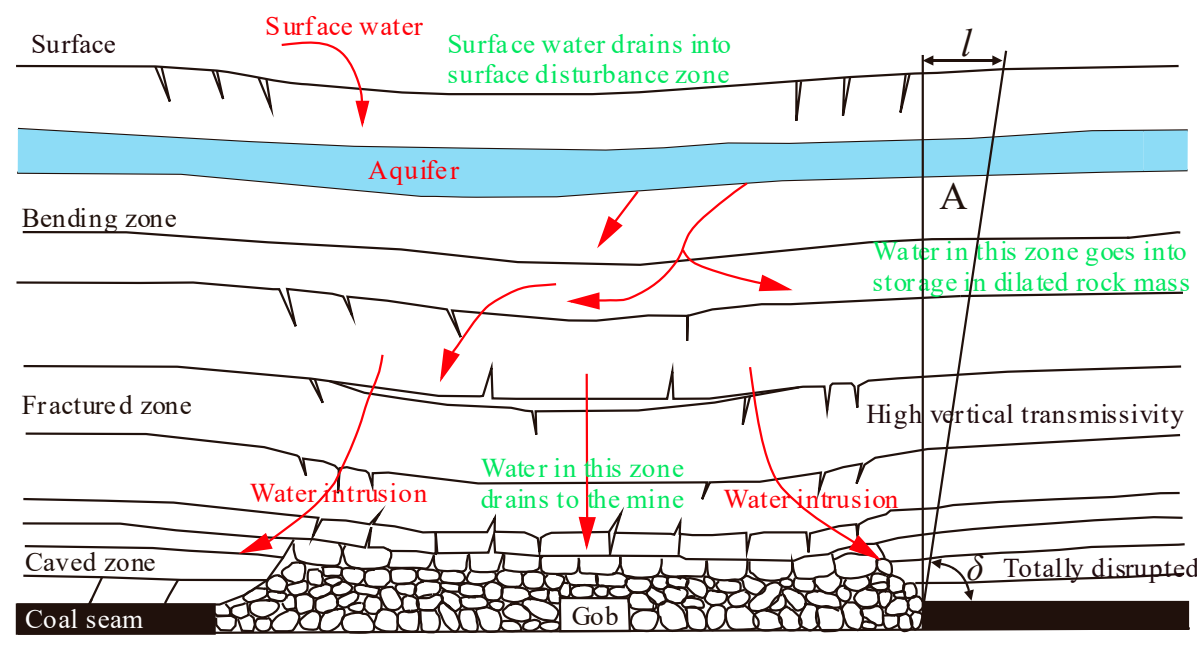

Figure 3. Three zones of strata movement above the coal seam (modified from Feng's work [19]).

For the longwall face beneath the aquifer, the key to safe mining lies in the determination of whether the WFFZ can connect to the aquifer. Because the unconfined aquifer under the river has strong lateral recharge capacity, and the water conductivity of WFFZ is greatly enhanced compared to the original strata, the connection of the WFFZ and aquifer will lead to the downward flow of water. This will greatly increase the risk of water inrush accidents. Therefore, it has great significance to accurately determine the height of the WFFZ to ensure mining safety of 8101 longwall face.

\section{Materials and Methods}

\subsection{Determination Methods of the Height of the WFFZ}

Many scholars have calculated the height of the WFFZ. Peng et al. [18] performed a large amount of work on the mining destruction of the overlying strata in the U.S. and concluded that the height of the WFFZ can develop 30-50 times the mining thickness. Palchik et al. [20] noted that the height of the WFFZ can develop to 20-100 times the mining thickness. Qian et al. [21] performed many theoretical studies and field surveys on overburden rock failure in coal mines in China, concluding that the height 
of the WFFZ is dependent on the rock lithology and mining thickness. A harder lithology and a larger mining thickness lead to a higher WFZZ. In general, the height of the WFFZ is 9-12 times the mining thickness for weak strata, 12-18 times the mining thickness for medium-hard strata and 18-28 times the mining thickness for hard strata. Through theoretical analyses and field tests in China, an empirical formula was developed by the National Bureau of Coal Industry of China to calculate the height of the WFFZ [22]. The empirical formula satisfied the design of mining beneath water for most coal mines in China at that time and was widely used to calculate the height of the WFFZ in China. However, the empirical formula is applicable only when the mining thickness ranges from 1.0 to $3.0 \mathrm{~m}$ due to the limited technical level of coal mines at that time. The empirical formula is as follows:

$$
\mathrm{H}=\frac{100 \sum M}{p_{1} \sum M+p_{2}} \pm q
$$

where $\mathrm{H}$ is the height of WFFZ, $\mathrm{m} ; M$ is the mining height, $\mathrm{m} ; p_{1}$ and $p_{2}$ are coefficients determined by the overlying rock strata lithology; $\pm q$ is the root mean square error.

In addition, there are borehole water injection (discharge) fracture measuring systems, borehole teleview logging systems [3,4], radon detection technology [23] and microseismic monitoring technology [24] to determine the height of the WFFZ. These methods are intuitive, precise and effective and widely used in coal mines. Wei et al. [25] combined various detection methods with physical and numerical simulations to determine the height of the WFFZ after mining, and the results were reliable. However, the methods above have limitations to varying degrees. For the longwall face with a mining height larger than $3 \mathrm{~m}$, the empirical formula is not applicable. The latter can only detect fractures that have developed in the boreholes after mining, and the data from several boreholes are not enough to obtain the fracture development for the entire longwall face.

\subsection{TEM Method and Field Setup}

The working principle of the TEM method is shown in Figure 4. Generally, a current with a certain waveform (generally square wave) is passed through a transmitting coil. A pulsed primary electromagnetic field is generated in front of it. When the current is turned off, the primary electromagnetic field gradually decays and then disappears. The underground geological body generates an induced eddy current, which generates an attenuated secondary field carrying the electrical properties of the geological body. The receiving coil records the induced electromotive force of the secondary field. Then we can analyze the distribution rules of the underground geological body.

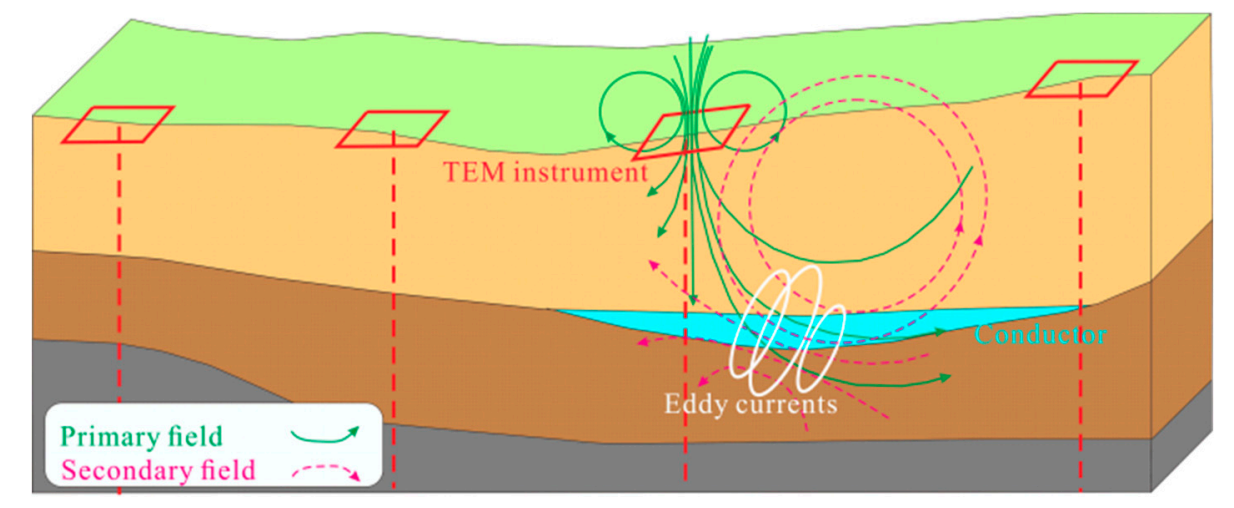

Figure 4. Working principle of the transient electromagnetic (TEM) method.

During data processing, late-time apparent resistivities can be calculated from the measured induced electromotive force using the following equation [26]: 


$$
\rho=\frac{\mu_{0}}{4 \pi t}\left(\frac{2 \mu_{0} S S_{0}}{5 t \cdot \frac{\epsilon^{h}(t)}{I_{0}}}\right)^{\frac{2}{3}}
$$

where $\rho$ is the late-time apparent resistivity, $\Omega \cdot \mathrm{m} ; \mu_{0}$ is magnetic permeability $\mathrm{T} \cdot \mathrm{m} / \mathrm{A} ; t$ is time, s; $S$ is the transmitter loop area, $\mathrm{m}^{2} ; S_{0}$ is the receiver coil area, $\mathrm{m}^{2} ; \epsilon^{h}(t)$ is the measured induced electromotive force, $\mathrm{V} ; I_{0}$ is the transmitting current, $\mathrm{A}$.

The corresponding depths of the late-time apparent resistivities can be calculated using the following equation [27]:

$$
d=\sqrt{\frac{2 \rho t}{\mu_{0}}}
$$

To obtain the apparent resistivity distribution of each survey line, Equations (3) and (4) were used to calculate $\rho$ and $d$. Through data processing and apparent resistivity mapping, the following results are obtained.

According to the geological conditions of the 8101 longwall face, the central loop TEM method was adopted to survey the riverbed above the longwall face (Figure 5). The parameters are as follows: the transmitting voltage is $24 \mathrm{~V}$, the transmitting current is $2 \mathrm{~A}$, and the transmitting frequency is $25 \mathrm{HZ}$ (time range of $0.08-8.4 \mathrm{~ms}$ ). The multiturn transmitter loop is $2.0 \mathrm{~m} \times 2.0 \mathrm{~m}$ with 64 turns, and the multiturn circular receiver loop is 40 turns with a diameter of $1.0 \mathrm{~m}$. The survey area is a parallelogram with the adjacent sides $300 \mathrm{~m}$ and $100 \mathrm{~m}$ in length. There are three survey lines in the survey area, with 30 survey points in each line. The point spread is $10 \mathrm{~m}$, and the line spread is $30 \mathrm{~m}$.

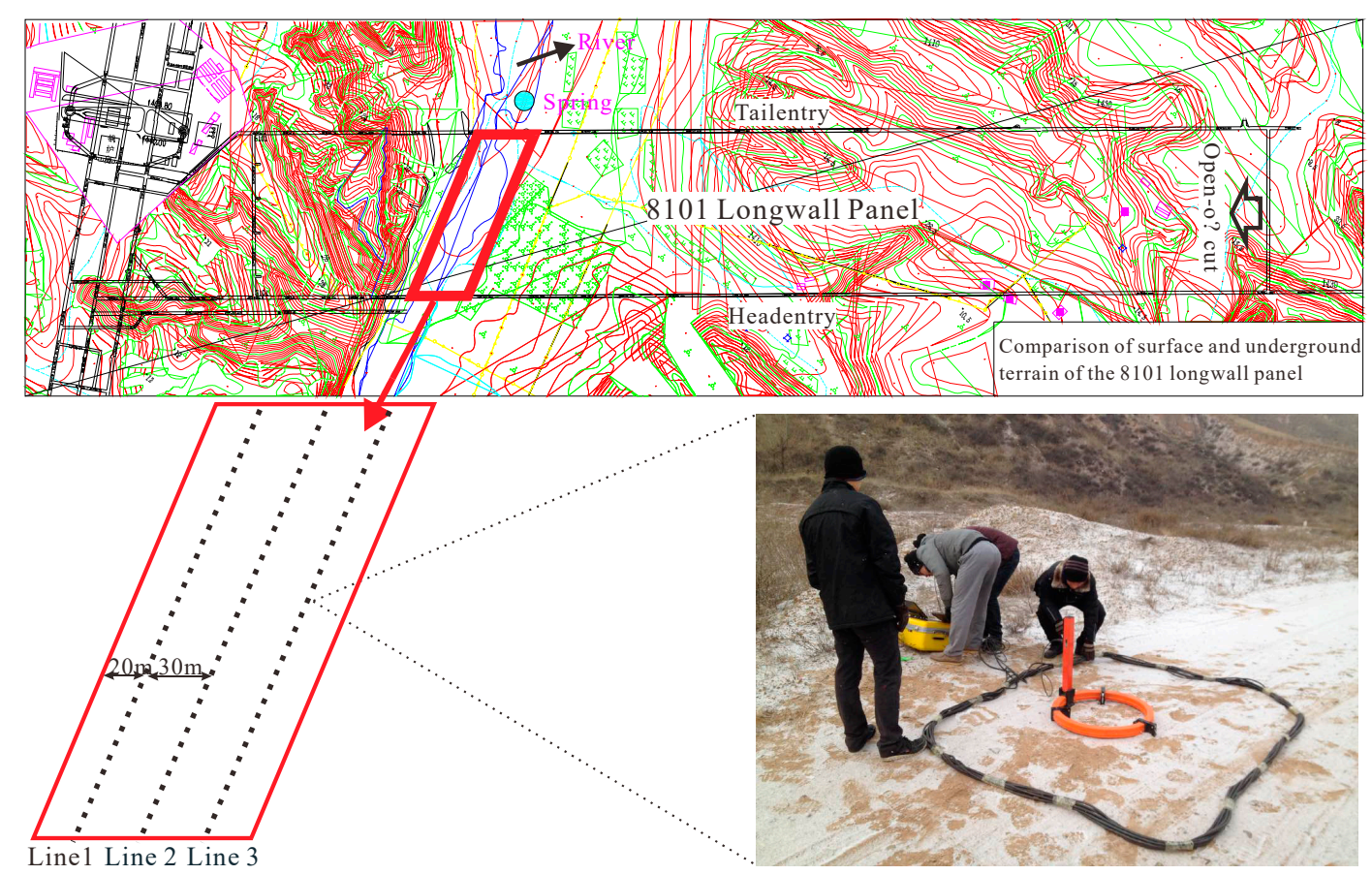

Figure 5. The layout of the survey area. The red quadrangle refers to the survey area. The colored lines refer to the contours of the surface terrain of the 8101 longwall face. The black lines refer to roadways. The points in the lower left corner refer to the survey stations. In the lower right corner, the black coil is the transmitter loop, the orange coil is the receiver loop, and the yellow device is the TEM transmitter and receiver instrument.

\subsection{Curve Fitting and Numerical Modeling Method}

To compare the change behavior of the water levels from TEM results more intuitively, the water levels of each survey station were extracted every day for curve fitting with MATLAB (R2014b, The 
MathWorks Inc., Natick, MA, US 2014) We adopted the rational polynomials method, which had the best fitting result. The main advantage of the rational polynomials method is its flexibility with data that has a complicated structure.

The rational polynomials equation is defined as:

$$
\mathrm{y}=\frac{\sum_{i=1}^{n} p_{i} x^{n-i}}{x^{m}+\sum_{i=1}^{m} q_{i} x^{m-1}}
$$

where $n$ is the degree of the numerator polynomial and $m$ is the degree of the denominator polynomial. Through comparison, we finally chose the cubic/linear rational equation as the governing equation of curve fitting.

After comparing the change behavior of the water levels, a 2D finite-element numerical model developed with COMOSL (3.5a, COMSOL Inc., Stockholm, SWE 2018) Multiphysics was designed to study the lateral recharge and water seepage mechanisms of the aquifer. According to the geological conditions of the 8101 longwall face, the water seepage model was built based on the conservation of mass and the pressure equilibrium. The model consists of three parts, representing the overlying aquifer, the WFFZ and the roadway of the 8101 longwall face. The upper part is $100 \mathrm{~m}$ wide and $20 \mathrm{~m}$ thick, representing the $K_{1 z h}$ unconfined aquifer in the lower series of the Cretaceous and the middle Jurassic coarse sandstone aquifer, and the corresponding physical field is Darcy flow. The middle part is $10 \mathrm{~m}$ wide and $100 \mathrm{~m}$ thick, and the corresponding physical field is high-speed Forchheimer flow, representing the water flowing fractured zone. The middle part was set on the right side of the model to simulate the case that the WFFZ connected to the corner of the aquifer. The lower part is $100 \mathrm{~m}$ wide and $5 \mathrm{~m}$ thick, representing the roadway of the 8101 working face, and the corresponding physical field is Navier-Stokes flow. The model is shown in Figure 6. The finite element method with local mesh refine strategy was adopted, and the model was divided into 7314 triangular elements.

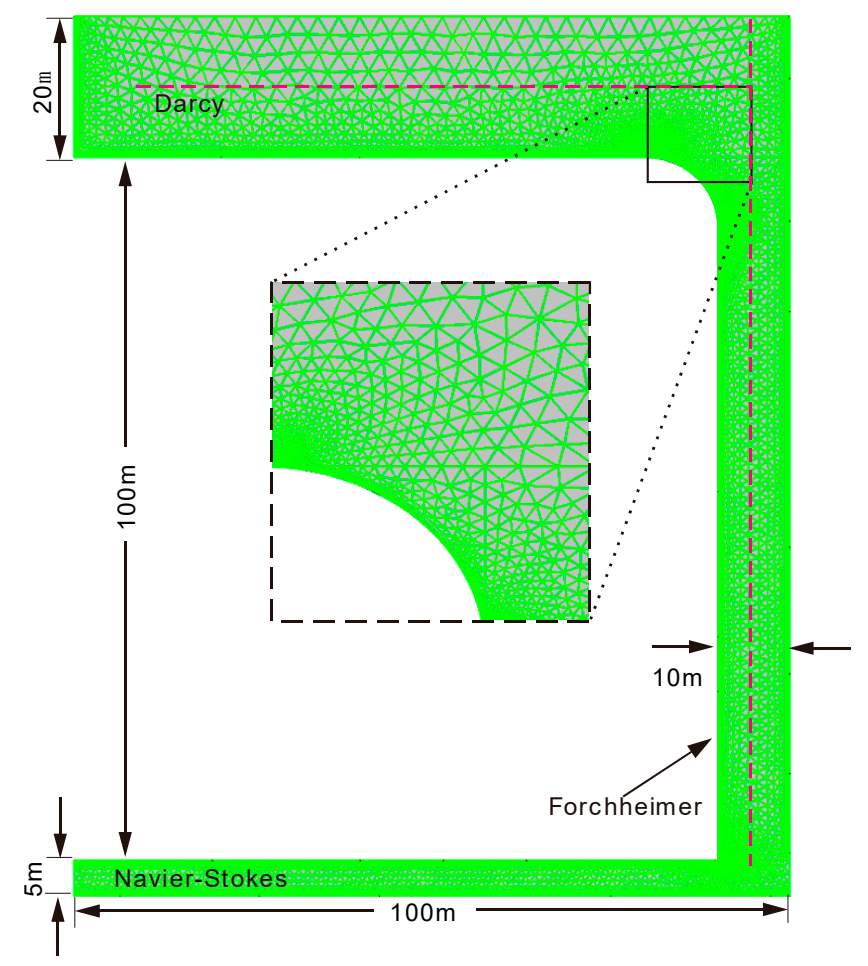

Figure 6. The numerical model of water seepage in the water flowing fractured zone (WFFZ). The horizontal red dotted cut line was used to extract the corresponding water flow velocity in the aquifer, and the vertical one was used to extract the water flow velocity in the WFFZ and the corresponding aquifer area. 
The seepage of water in aquifers obeys Darcy's law [28] as follows:

$$
\boldsymbol{u}=-\frac{k}{\eta}(\nabla p+\rho g Z)
$$

where $u$ is the flow velocity of water $(\mathrm{m} / \mathrm{s}), k$ is the rock permeability $\left(\mathrm{m}^{2}\right), \eta$ is the dynamic viscosity $(\mathrm{Pa} \cdot \mathrm{S}), \mathrm{Z}$ is the hydraulic head $(\mathrm{m}), \rho$ is the fluid density $\left(\mathrm{kg} / \mathrm{m}^{3}\right), g$ is the gravitational acceleration $\left(9.8 \mathrm{~m} / \mathrm{s}^{2}\right)$, and $\nabla$ is the gradient operator.

The flow of water in the WFFZ obeys the Ahmed-Sunada (Forchheimer) relation, and the equations of motion, continuity and state are as follows [29]:

$$
\begin{gathered}
\rho C_{a} \frac{\partial u}{\partial t}-\beta \rho \boldsymbol{u} \boldsymbol{u}+\frac{\eta}{k} \boldsymbol{u}+\nabla p=f \\
\frac{\partial(\varnothing \rho)}{\partial t}+\nabla \cdot(\rho \boldsymbol{u})=\rho q \\
\varnothing=\varnothing_{0}\left[1+c_{\varnothing}\left(p-p_{0}\right)\right]
\end{gathered}
$$

where $C_{a}$ is the acceleration coefficient, $\beta$ is the non-Darcy factor, $q$ is the source intensity, $p_{0}$ is the initial pressure $(\mathrm{Pa}), \varnothing_{0}$ is the initial porosity, $c_{\varnothing}$ is pore compressibility, and $\nabla$ is the divergence operator.

The flow of water in the roadway is mainly free flow, obeying the Navier-Stokes equation [29]:

$$
\left\{\begin{array}{c}
\rho \frac{\partial u}{\partial t}-\eta \nabla \cdot\left(\nabla \boldsymbol{u}+\nabla \boldsymbol{u}^{T}\right)+\rho \boldsymbol{u} \nabla \boldsymbol{u}+\nabla p=f \\
-\nabla \cdot \boldsymbol{u}=0
\end{array}\right.
$$

The initial flow velocity of the model was $0 \mathrm{~m} / \mathrm{s}$, and the initial pressure was atmospheric pressure (the relative pressure was $0 \mathrm{~Pa}$ ). The stable water inflow boundaries were set on the top of the aquifer at $t=0 \mathrm{~s}$, and the inflow velocity was $1.0 \times 10^{-3} \mathrm{~m} / \mathrm{s}$. The water inflow was removed at $t=4000 \mathrm{~s}$ in order to simulate the water flow mechanisms under limited water content. The outlet boundaries were set on both sides of the roadway; the relative pressure was $0 \mathrm{~Pa}$. Other boundaries of the model were set as no-slip walls. According to the lithology of the overlying strata of the 8101 longwall face and the physical parameters of water, the parameters were set as shown in Table 1.

Table 1. The numerical simulation parameters.

\begin{tabular}{cccc}
\hline Parameter & Value & Parameter & Value \\
\hline Fluid density $\rho\left(\mathrm{kg} / \mathrm{m}^{3}\right)$ & 1000 & Non-Darcy factor $\beta$ & $2.5 \times 10^{-8}$ \\
Dynamic viscosity $\eta(\mathrm{Pa} \cdot \mathrm{S})$ & $1.01 \times 10^{-3}$ & Acceleration coefficient $\mathrm{c}_{\mathrm{a}}$ & 1.0 \\
Permeability of the aquifer $\left(\mathrm{m}^{2}\right)$ & $5.3 \times 10^{-11}$ & Initial porosity $\varphi_{0}$ & 0.25 \\
Permeability of the WFFZ $\left(\mathrm{m}^{2}\right)$ & $5.3 \times 10^{-10}$ & Pore compressibility $\mathrm{c}_{\varphi}$ & $1.45 \times 10^{-10}$ \\
\hline
\end{tabular}

\section{Results and Discussion}

According to the lithology of the overlying strata, the rock type is hard. The coefficients $p_{1}$ and $p_{2}$ of Equation (2) are 1.2 and 2.0, respectively, and $q$ is 8.9. The predicted height of the WFFZ is 49.9 to $67.7 \mathrm{~m}$. The nearest distance from the aquifer to the 8101 working face is $97.25 \mathrm{~m}$. Therefore, the WFFZ cannot reach the aquifer according to the empirical formula. But the empirical formula is only suitable for coal seam with the thickness of less than $3 \mathrm{~m}$. So the result from the empirical formula needs to be treated cautiously as the average thickness of the 8101 longwall face is $4 \mathrm{~m}$.

Before using the TEM method to detect the development of the WFFZ, this paper used the observation results of the surface cracks to guide the TEM survey schedule. During the extraction, the fractures in the overlying strata are developed in advance. The ground geological survey was carried out before the longwall face reached the riverbed. Based on the ground observation, the distance of the advanced influence is, on average, $14.1 \mathrm{~m}$ ahead of the working face (Table 2). As the advanced 
distance is related to the moving angle of the terrane, the angle of the advanced influence was obtained using Equation (1) to guide the TEM survey. The average depth of the coal seam is $170 \mathrm{~m}$, so the angle of the advanced influence $\delta=85.3^{\circ}$. When the working face reaches the riverbed, the average depth of the coal seam is $125 \mathrm{~m}$. The corresponding distance of the advanced influence should be $12.2 \mathrm{~m}$.

Table 2. The development of surface cracks after the first weighting and periodic weighting.

\begin{tabular}{|c|c|c|c|c|c|}
\hline \multirow{2}{*}{ No. } & \multirow{2}{*}{$\begin{array}{c}\text { Weighting } \\
\text { Distance }\end{array}$} & \multirow{2}{*}{ Scope } & \multicolumn{2}{|c|}{ Fracture } & \multirow{2}{*}{ Notes } \\
\hline & & & Width & Depth & \\
\hline 1 & $40.5 \mathrm{~m}$ & $-44.8 m+29.3 m$ & $50-60 \mathrm{~cm}$ & $7-8 \mathrm{~m}$ & \multirow{9}{*}{$\begin{array}{c}\text { Periodic Weighting } \\
\text { The average distance of the advanced influence: } \\
14.1 \mathrm{~m} \\
\text { The average width of the fractures: } \\
17.5 \mathrm{~cm}\end{array}$} \\
\hline 1 & $17.3 \mathrm{~m}$ & $+11.9 \mathrm{~m}$ & $30 \mathrm{~cm}$ & $2.5 \mathrm{~m}$ & \\
\hline 2 & $15.7 \mathrm{~m}$ & $+14.0 \mathrm{~m}$ & $18 \mathrm{~cm}$ & $1.7 \mathrm{~m}$ & \\
\hline 3 & $16.8 \mathrm{~m}$ & $+12.0 \mathrm{~m}$ & $20 \mathrm{~cm}$ & $2.0 \mathrm{~m}$ & \\
\hline 4 & $17.7 \mathrm{~m}$ & $+14.1 \mathrm{~m}$ & $15 \mathrm{~cm}$ & $1.8 \mathrm{~m}$ & \\
\hline 5 & $14.7 \mathrm{~m}$ & $+16.1 \mathrm{~m}$ & $10 \mathrm{~cm}$ & $1.0 \mathrm{~m}$ & \\
\hline 6 & $15.1 \mathrm{~m}$ & $+14.3 \mathrm{~m}$ & $12 \mathrm{~cm}$ & $1.0 \mathrm{~m}$ & \\
\hline 7 & $15.4 \mathrm{~m}$ & $+15.8 \mathrm{~m}$ & $16 \mathrm{~cm}$ & $1.3 \mathrm{~m}$ & \\
\hline 8 & $15.3 \mathrm{~m}$ & $+14.6 \mathrm{~m}$ & $19 \mathrm{~cm}$ & $1.8 \mathrm{~m}$ & \\
\hline
\end{tabular}

\subsection{TEM Survey Results}

The field experiment was carried out before the longwall face reached the riverbed. Some of the results are shown in Figures 7 and 8. The curves of the induced electromotive forces with a slow decay indicate that a good conductor exists in this area, and the resistivity in this area is low (Figure 7). A poor conductor would result in a fast decay. Furthermore, the late time-induced electromotive force derived from a good conductor would be higher than that derived from a poor conductor (areas bordered in red in Figure 8). In other words, the resistivity of the water-bearing area is much lower than that of the area without water.

As the distance of the advanced influence should be $12.2 \mathrm{~m}$ when the longwall face reached the riverbed, the experimental survey was carried out when the longwall face reached $1245.5 \mathrm{~m}$ on January 27th. The distance between the longwall face and the riverbed was $24.5 \mathrm{~m}$ on that day. The survey lasted from January 28th to February 9th, with 90 survey points each day and 13 days in total. Because we encountered a snowstorm during the survey process on February 7th, only 30 survey points were measured on that day. The total number of survey points is 1110 .

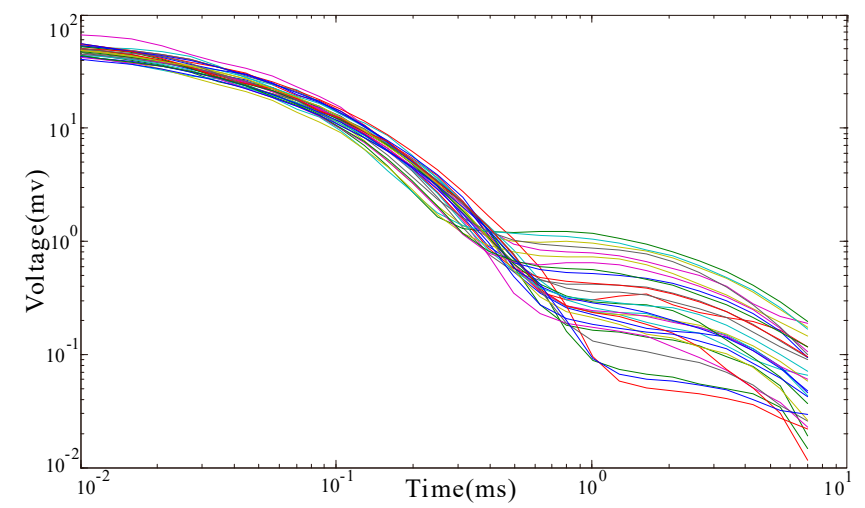

Figure 7. Comparison of the different field experiment results. The horizontal axis represents time, and the vertical axis represents the induced voltage; both are logarithmic. The different colored lines refer to the curves of induced electromotive forces derived from the different survey stations.

The 8101 longwall face position during the survey period is shown in Table 3. The footage of the working face is $1251.5 \mathrm{~m}$ on the first day of the survey, and the distance between the survey area and the working face is $18.5 \mathrm{~m}$. Although there might be a fractured zone ahead of the working face, the fracture could not reach the overlying aquifer. 


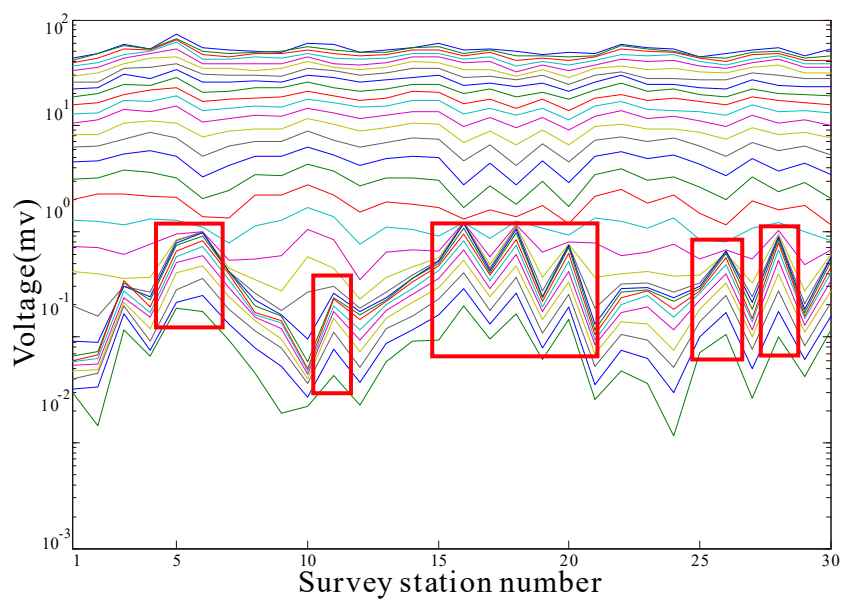

Figure 8. Comparison of the late time-induced electromotive forces. The horizontal axis represents the survey station number, the vertical axis represents the induced voltage, and the latter is logarithmic. The different colored lines refer to the curves of the induced electromotive forces of the different survey stations at the same time.

Table 3. The 8101 longwall face position during the survey.

\begin{tabular}{ccc}
\hline Day & Date & Position $(\mathbf{m})$ \\
\hline 1 & Jan. 28th & 1251.5 \\
2 & Jan. 29th & 1265.5 \\
3 & Jan. 30th & 1275.7 \\
4 & Jan. 31st & 1283.3 \\
5 & Feb. 1st & 1294.4 \\
6 & Feb. 2nd & 1302.0 \\
7 & Feb. 3rd & 1313.1 \\
8 & Feb. 4th & 1319.0 \\
9 & Feb. 5th & 1326.7 \\
10 & Feb. 6th & 1336.9 \\
11 & Feb. 7th & 1345.4 \\
12 & Feb. 8th & 1350.5 \\
13 & Feb. 9th & 1355.8 \\
\hline
\end{tabular}

Figure 9 shows the TEM results without mining influence. The low resistivity area at a depth of 20-40 m corresponds to the $\mathrm{K}_{\mathrm{lzh}}$ unconfined aquifer in the lower series of the Cretaceous and the middle Jurassic coarse sandstone aquifer. The water level and volume of the aquifer remained unchanged without mining influence.

Figure 10 shows the results of the TEM survey during the mining process. Combining the survey results and the position of the 8101 longwall face, the change of the water level and the development of the WFFZ during the mining process can be analyzed.

The survey results of line 1 are shown in Figure 10a. The footage of the longwall face on the first day of the survey was $1251.5 \mathrm{~m}$, and the survey area was not affected by mining. The arrow indicates the location of the $\mathrm{K}_{\mathrm{lzh}}$ unconfined aquifer (apparent resistivity $15 \Omega \cdot \mathrm{m}$ and below, at a depth of approximately $20-40 \mathrm{~m}$ ). The water level was stable. Affected by mining, the water from the overlying aquifer began to flow down (to $60 \mathrm{~m}$ and below) by the second day. By the 4th day, the low resistivity area near a depth of $40 \mathrm{~m}$ had migrated downward to $60-80 \mathrm{~m}$. This indicates that the water from the overlying aquifer continued to flow downward, and the yield of water decreased significantly compared to the second day. By the 8th day, the low resistance area near the original aquifer gradually disappeared, indicating that the water had moved downward to 80-100 $\mathrm{m}$. Along with the diffusion of the low resistivity area, the resistivity became higher because there was no water 
supply from the surface. By the 13th day, the low resistivity area was almost the same as the 8th day, only more inconspicuous. The water distribution in the overlying strata had become stabilized.

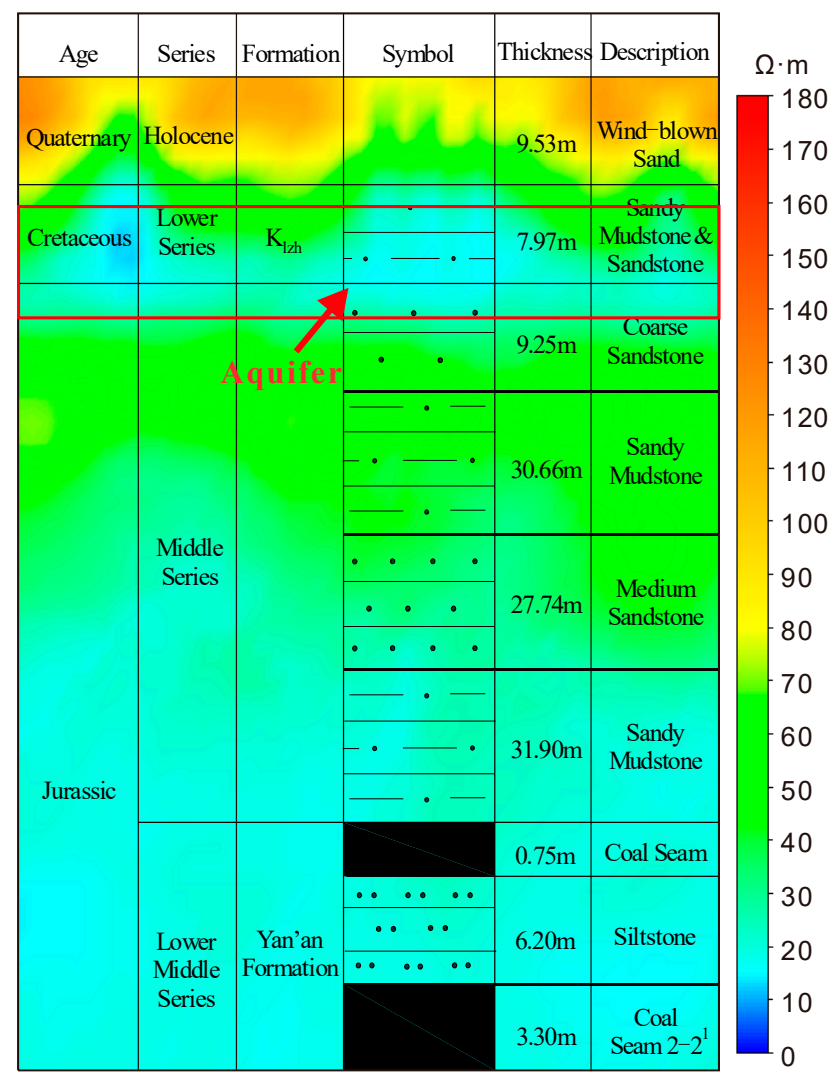

Figure 9. Comparison of the TEM observation results and the geological log profile. The cyan area is the low resistivity zone, with a depth of $20-40 \mathrm{~m}$ and an apparent resistivity value of $15 \Omega \cdot \mathrm{m}$ and below.

The survey results of line 2 are shown in Figure 10b. The arrow indicates the location of the aquifer (apparent resistivity $15 \Omega \cdot \mathrm{m}$ and below, at a depth of approximately $60-100 \mathrm{~m}$ ). The water level was stable. The results of line 2 showed that the water level of the aquifer was relatively low. The different water levels of line 2 could result from fault(s) in the overlying strata, as the fault zone is often filled with water, and the nearby water level will be affected. If the fault zone is disturbed by mining, the fault structure will form a water flowing channel, and the water transmitting ability of it will be greatly enhanced [30,31]. By the second day, the resistivity of this area became higher, indicating a reduction of the water volume. By the 4 th day, the water content continued to decrease and moved further downward (the resistivity of the area near 100-130 m became lower). By the 8th day, the water had almost finished moving downward (the low resistance area near the original aquifer gradually disappeared). By the 13th day, the low resistivity area was almost the same as the 8th day, only more inconspicuous. The water distribution in the overlying rock strata had become stabilized.

The survey results of line 3 are shown in Figure 10c. The arrow indicates the location of the $\mathrm{K}_{\mathrm{lzh}}$ unconfined aquifer (apparent resistivity $15 \Omega \cdot \mathrm{m}$ and below, at a depth of approximately $20-40 \mathrm{~m}$ ). The water level was stable. By the second day, the water from the overlying aquifer had begun to flow down (to $60 \mathrm{~m}$ and below). By the 4th day, the low resistivity area near $40 \mathrm{~m}$ had migrated downward to $60-100 \mathrm{~m}$. This indicates that the water from the overlying aquifer continued to flow downward through the WFFZ, and the yield of water decreased significantly compared to the second day. By the 8th day, the low resistance area near the original aquifer had gradually disappeared, indicating that the mining fractures had connected to the aquifer and the water had moved downward to $70-100 \mathrm{~m}$. 
By the 13th day, the low resistivity area was almost the same as the 8th day, only more inconspicuous. The water distribution in the overlying rock had become stabilized.

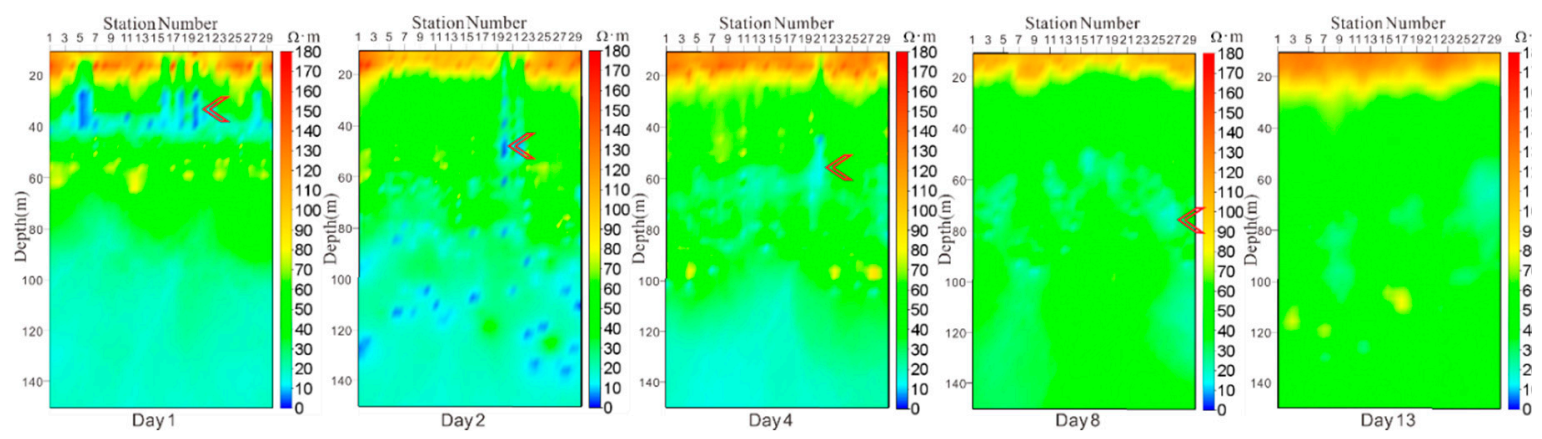

(a) line 1
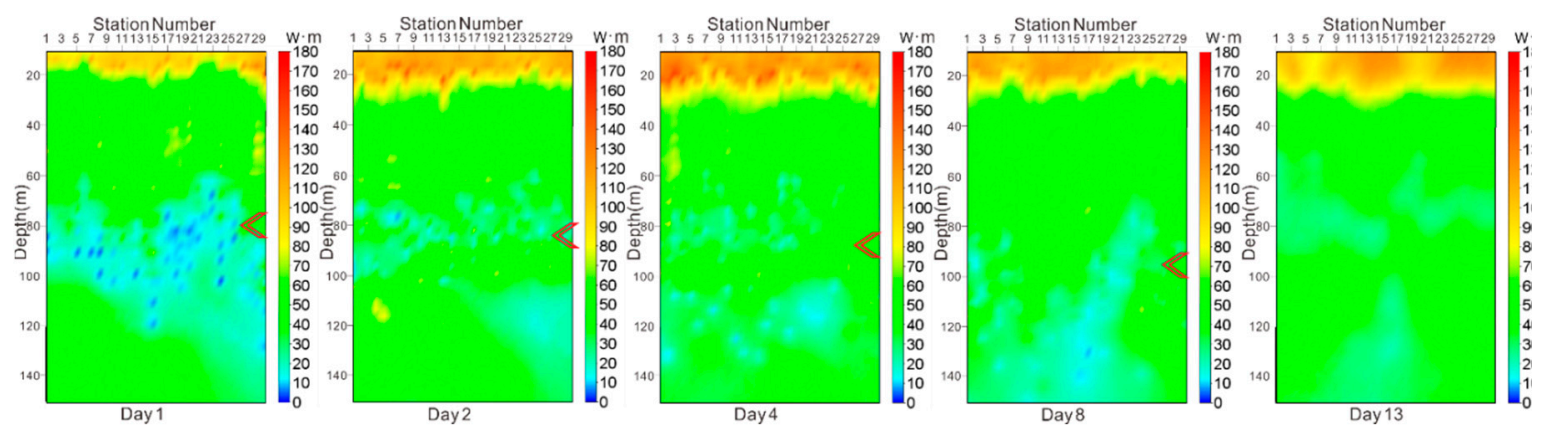

(b) line 2
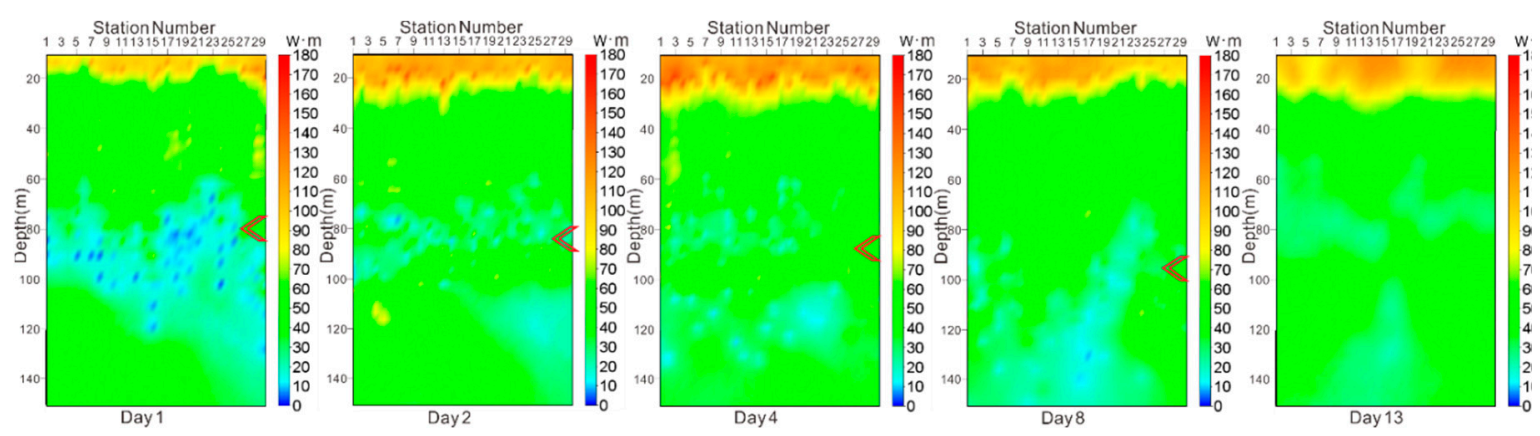

(c) line 3

Figure 10. The results of the TEM survey during the mining process. The horizontal axis represents the survey station number, and the vertical axis represents the depth $(\mathrm{m})$. The color bar represents the apparent resistivity $(\Omega \cdot \mathrm{m})$. The arrow indicates the location of the aquifer.

\subsection{Curve Fitting of the Water Levels}

Through curve fitting, the change behavior of the water level for each survey line was obtained (Figure 11). It is obvious that the water levels of each survey line declined quickly during the mining process. After a short-term and rapid downward move, the seepage slowed down, and the water level tended to be stable because there was no surface water supply. The decline of the water level in line 1 lasted for three days, and the water tended to be stable after the 4th day of the survey. The decline times of line 2 and line 3 are two days and four days, respectively. The change rate of the water level for lines 1 and 3 are similar, while the change rate for line 2 is relatively fast. As mentioned before, the different change rates of line 2 could result from fault(s) in the overlying strata. 


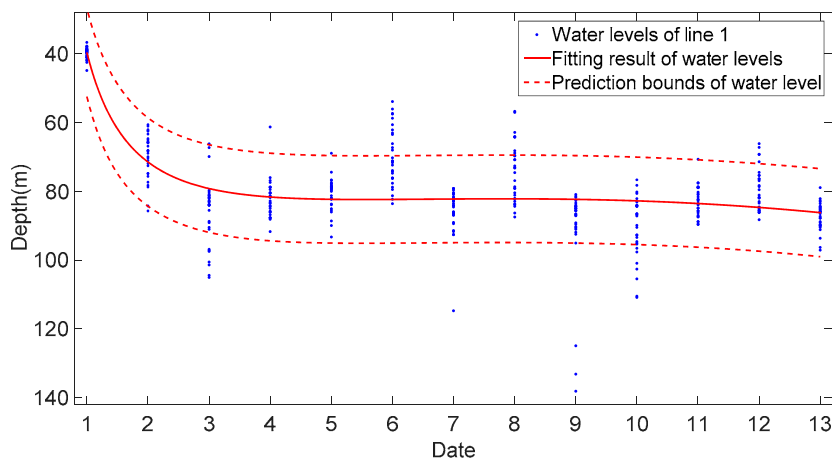

(a) line 1

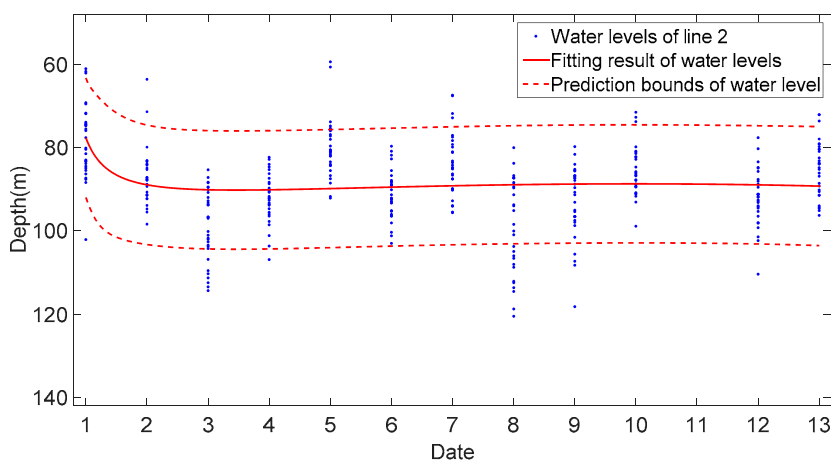

(b) line 2

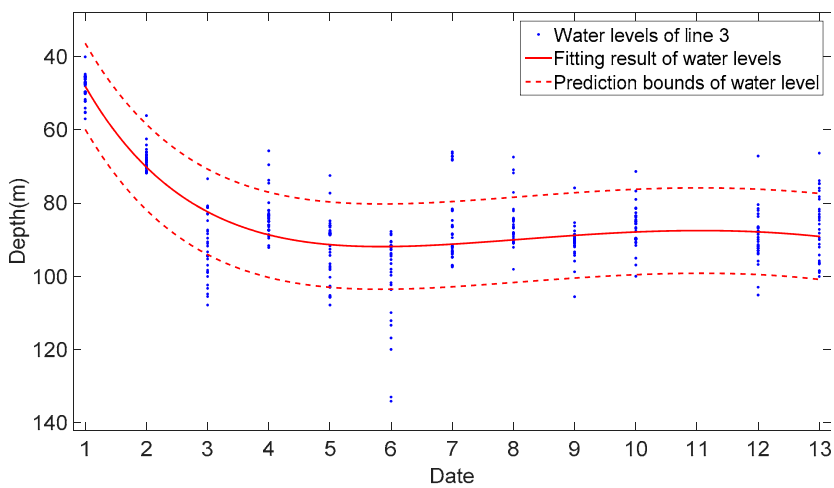

(c) line 3

Figure 11. Fitted curves of the water level change. The blue points represent the water levels of each survey station, and the red solid line represents the curve fitting result of the water levels. The red dotted lines are the prediction bounds of the curve fitting result (with $95 \%$ confidence), representing the distribution band of the water levels. To ensure the curve fitting quality, the outliers were excluded.

Figure 12 shows the comparison of water levels of different survey stations. The water level was stable on the 1st day. On the 2nd day of the survey, the longwall face reached $1265.5 \mathrm{~m}$. The distance from longwall face to the 1st survey station of line 3 was $6.3 \mathrm{~m}$. As mentioned before, the advanced fractures could connect to the $\mathrm{K}_{\mathrm{lzh}}$ unconfined aquifer at the location of 1 st survey station of line 3 . The distances from longwall face to the other three survey stations were $119.3 \mathrm{~m}, 66.3 \mathrm{~m}$ and $179.3 \mathrm{~m}$ for 30th survey station of line 3, 1st survey station of line 1 and 30th survey station for line 1, respectively. Although the latter three survey stations had a certain distance from the working face, the water level at these positions all declined obviously. This illustrates that the Klzh unconfined aquifer has a strong 
lateral recharge capacity. When the water level declined at a position of the aquifer, the lateral seepage occurred to recharge this position. Because the water content of the aquifer was limited, the water level of the whole aquifer under the riverbed was affected when the advanced fractures reached the aquifer. The water level decreased most from the 1st day to the 2nd day, gradually decreased from the 2nd day to the 4 th day, and gradually stabilized after the 4 th day.

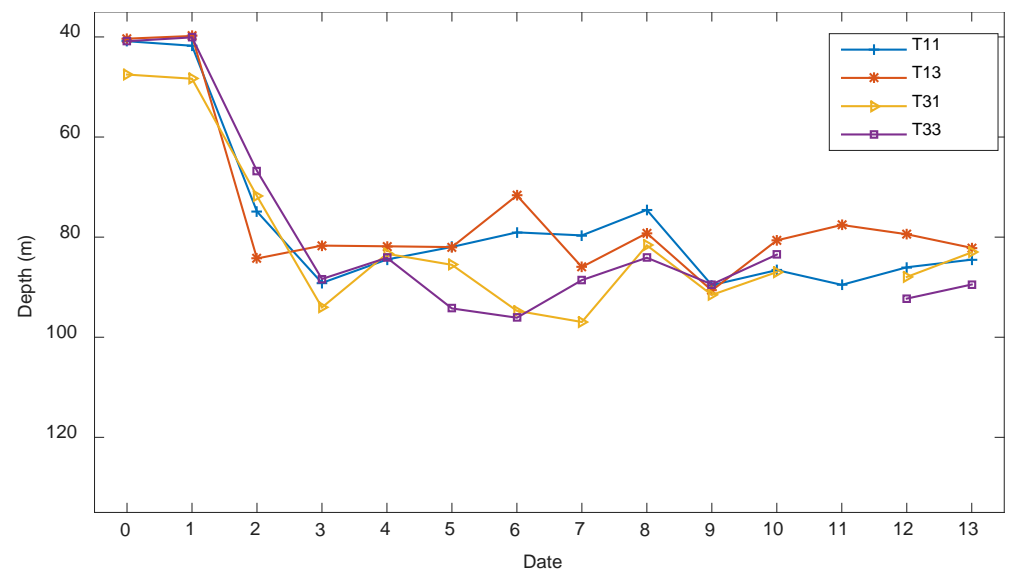

Figure 12. Comparison of water levels of different survey stations. The horizontal axis represents the survey days, and the vertical axis represents the water levels. The data of day 0 is the experimental data. T11 represents the survey data of 1st survey station of line 1 . T13 represents the survey data of 30th survey station of line 1 . T31 represents the survey data of 1st survey station of line 3 . T33 represents the survey data of 30th survey station of line 1.

\subsection{D Modeling Results}

Figure 13 shows the water flow velocity of the vertical cut line. The flow velocity was $0 \mathrm{~m} / \mathrm{s}$ at $t=0 \mathrm{~s}$. When the water inflow was loaded (simulating the connection between the WFFZ and the aquifer), the water began to flow down. The flow velocity increased quickly and then tended to be stable after $t=2000 \mathrm{~s}$. The maximum flow velocity of the model reached $1 \times 10^{-2} \mathrm{~m} / \mathrm{s}$ at $t=4000 \mathrm{~s}$. As there was no water supply, the flow velocity gradually decreased after $t=4000 \mathrm{~s}$ and tended to be stable after $t=6000 \mathrm{~s}$, with the maximum flow velocity of $1.5 \times 10^{-5} \mathrm{~m} / \mathrm{s}$. In the vertical direction, the water flow velocity increased from the top of the aquifer to the roadway. The flow velocity reached the maximum at the position of $30 \mathrm{~m}$ (under the entrance of the WFFZ). As can be seen from Figure 13, there is an inflection of a sudden increase in flow velocity at $1 \mathrm{~m}$ beneath the top of the aquifer. That is because the flow velocity at the top of the aquifer was not affected by the lateral seepage while the lower part was affected. At the position of $20 \mathrm{~m}$ on the vertical line, another inflection of sudden increase occurred due to the great change of permeability and porosity at the interface of the aquifer and WFFZ. After a rapid increase, the flow velocity tended to be stable in the WFFZ. 


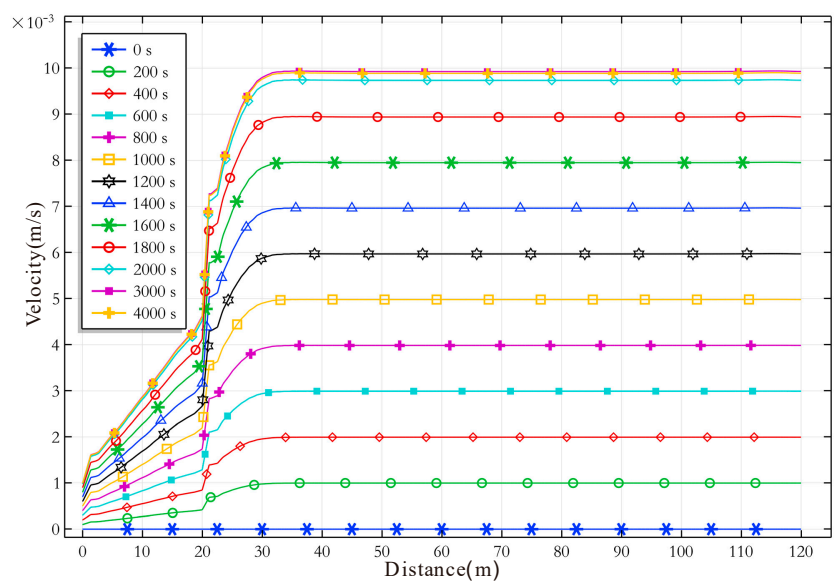

(a) $t=0-4000 \mathrm{~s}$

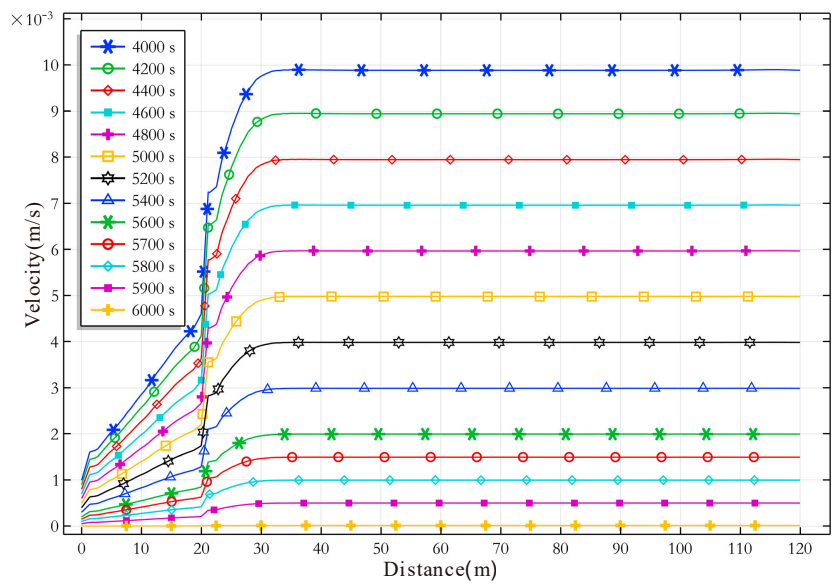

(b) $t=4000-6000 \mathrm{~s}$

Figure 13. Water flow velocity curves of the vertical cut line at different times. The horizontal axis represents the distance from the top of the aquifer to the interface of the WFFZ and the roadway.

Figure 14 shows the water flow velocity of the horizontal cut line. The flow velocity in the aquifer also increased at first, then stabilized, decreased and finally stabilized. It can be seen that the lateral recharge phenomenon existed in the aquifer, which caused the increase of water flow velocity from left to right and reached the maximum at the position of $75 \mathrm{~m}$. The maximum flow velocity in the aquifer was $3.9 \times 10^{-3} \mathrm{~m} / \mathrm{s}$ at $t=4000 \mathrm{~s}$, and occurred at $20 \mathrm{~m}$ to the right boundary of the aquifer, which was above the interface between the aquifer and the WFFZ. During the decline process of the water flow velocity in the aquifer, the gap between the velocity of the left and right side became smaller. The maximum flow velocity declined to $5.5 \times 10^{-6} \mathrm{~m} / \mathrm{s}$ at $t=6000 \mathrm{~s}$, and the flow velocity at $50 \mathrm{~m}$ was $4.1 \times 10^{-6} \mathrm{~m} / \mathrm{s}$. Since there was still an area of aquifer between them, it can be considered that the downward flow of water mainly came from the lateral recharge. Combining with Figure 15, the lateral recharge dominated the water flow at $t=6000 \mathrm{~s}$ and later. 


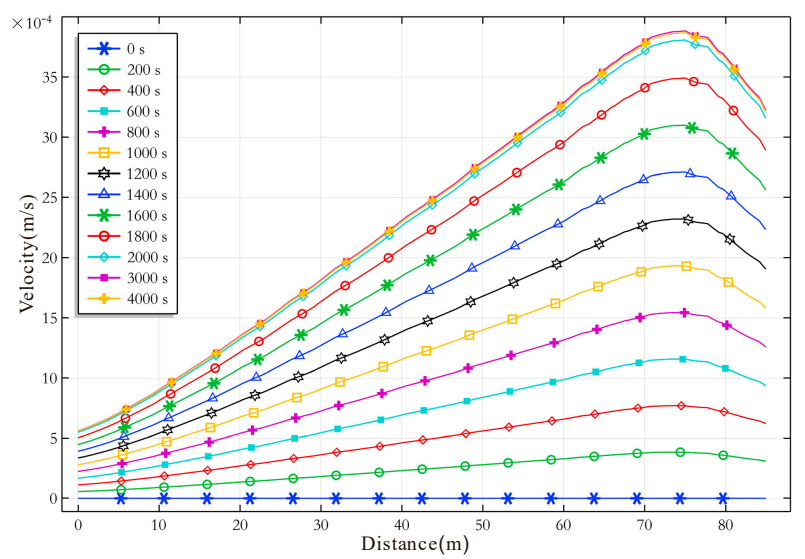

(a) $t=0-4000 \mathrm{~s}$

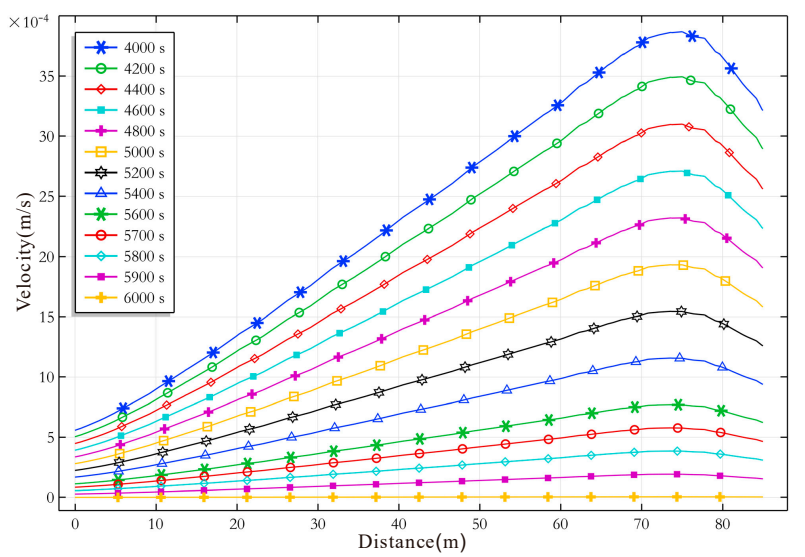

(b) $t=4000-6000 \mathrm{~s}$

Figure 14. Water flow velocity curves of the horizontal cut line at different times. The horizontal axis represents the distance from the left side of the aquifer to the right side.

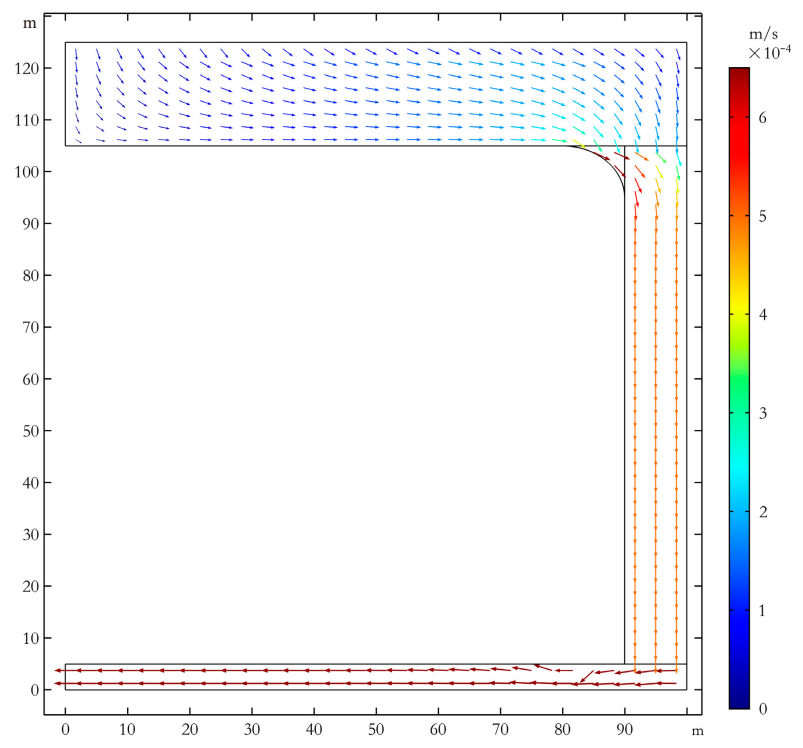

Figure 15. The velocity arrow of the model at $t=6000 \mathrm{~s}$. The color bar represents the flow velocity of the corresponding arrow. 


\subsection{Discussion}

The TEM survey revealed the distribution of the aquifers of the 8101 longwall face without mining influence and the water flow mechanisms during the mining process. The work confirmed that the TEM method can effectively detect the underground water distribution [10,13-15]. At the same time, the TEM survey results also showed that the WFFZ could connect to the aquifer, and that the height of the WFFZ was over $97.25 \mathrm{~m}$, which was 24-31 times the mining height. This is consistent with the result of Peng's work [18] and Palchik's work [20], and is much larger than the result of 49.9-67.7 m calculated from the empirical formula [3,32].

During the mining process of the 8101 longwall face, the water flow of the aquifer has some interesting characteristics. The 2D numerical and the TEM survey showed that the water quickly flowed down when the WFFZ connected to the overlying aquifer, which is consistent with the literature [29]. As there was no surface water supply, the water level gradually tended to be stable. The TEM survey confirmed the existence of lateral recharge phenomenon in the aquifer [33,34]; when the water level declined at a position of the aquifer, the lateral seepage occurred to recharge this position, leading to the decrease in the water level of the $\mathrm{K}_{\mathrm{lzh}}$ unconfined aquifer. In other words, although the damage of WFFZ was local, it affected the entire aquifer. Based on the TEM survey result, the 2D numerical simulation showed that the lateral recharge played an important role in aquifer water seepage [35] and even dominated the water flow in the late stage when the water volume of the aquifer was limited.

Because the TEM survey was carried out in the dry spell, the water volume was limited and the harm could be neglected. Since the 8101 longwall face is the first longwall face of Selian No.1 coal mine, when mining other longwall faces under this river, it is necessary to consider not only the influence of the corresponding aquifers and WFFZs but also the influence of the goaf and the WFFZ of 8101 longwall face. Therefore, it is necessary to take corresponding measures such as cutting off rivers, rock fracture grouting and other measures to ensure mining safety.

\section{Conclusions}

This paper first monitored the development of the WFFZ in the process of mining beneath a river with the TEM method. Detailed analysis found that the WFFZ reached the middle Jurassic coarse sandstone aquifer and the $\mathrm{K}_{\mathrm{lzh}}$ unconfined aquifer; in other words, the height of the WFFZ was over $97.25 \mathrm{~m}$, which was quite different from the $49.9-67.7 \mathrm{~m}$ calculated by empirical formula. Hence, it is not appropriate to calculate the height of the WFFZ only by the empirical formula when the mining height exceeds $3 \mathrm{~m}$. During the mining process, the rock fractures were developed in advance, and the downward seepage of water started before the longwall face reached the corresponding area. Combined with the numerical simulation results, we found that the water flowed downward quickly when the mining-induced water flowing fractures reached the overlying aquifer. The $\mathrm{K}_{\mathrm{lzh}}$ unconfined aquifer under the riverbed had a strong lateral recharge capacity, and when the water declined at the position closest to the longwall face, lateral seepage occurred to recharge this position. This caused a drop in the water level of the entire aquifer. As the river was in a dry spell, there was no surface water supply, the water storage of the aquifer was limited, and the flow slowed down after a short-term rapid downward movement. Finally, the water distribution of the overlying strata tended to be stable. During that period, roof water spraying occurred during the mining process. The harm was mainly caused by the lateral recharge of aquifer. Although it had a certain interference with the mining of the 8101 longwall face, the harm was limited. If the mining process had been carried out in the rainy season, the surface water would have continually moved downward into the longwall face, and the risk of water inrush accidents would be extremely high.

This research is focused on the development of the WFFZ of shallow buried coal seams. Further studies are needed in regard to the coal seam under the goaf, the deep buried coal seam or the repeated mining of close-distance coal seams. The data and results of this paper can provide a basis for the research of mining-induced water seepage mechanisms based on big data and the further study of the flow mechanisms of groundwater resources affected by mining. 
Author Contributions: S.C., Z.Y. and Z.M. conceived and designed the field survey; S.C., C.G., X.W., Z.Y. and Z.M. carried out the TEM detection; S.C., X.W. and C.G. processed and analyzed the TEM data; S.C. and X.W. designed and carried out the numerical experiment; S.C., Z.Y. and C.G. wrote this paper.

Funding: This research was funded by National Natural Science Foundation of China (No. 51174193).

Conflicts of Interest: The authors declare no conflict of interest.

\section{References}

1. Zhang, J.; Shen, B. Coal mining under aquifers in China: A case study. Int. J. Rock Mech. Min. Sci. 2004, 41, 629-639. [CrossRef]

2. Liu, T. Coal Mine Ground Movement and Strata Failure, 1st ed.; China Coal Industry Publishing House: Beijing, China, 1981; pp. 165-214.

3. Miao, X.; Cui, X.; Wang, J.; Xu, J. The height of fractured water-conducting zone in undermined rock strata. Eng. Geol. 2011, 120, 32-39. [CrossRef]

4. Gao, B.; Liu, Y.; Pan, J.; Yuan, T. Detection and analysis of height of water flowing fractured zone in underwater mining. Chin. J. Rock Mech. Eng. 2014, 33, 3384-3390. [CrossRef]

5. Yao, B.; Bai, H.; Zhang, B. Numerical simulation on the risk of roof water inrush in Wuyang Coal Mine. Int. J. Min. Sci. Technol. 2012, 22, 273-277. [CrossRef]

6. Zhu, H.; Yi, C.; Jiang, Y.; Xie, H.; Yang, M. Effect of fractures cross connection on fluid flow characteristics of mining-induced rock. J. China Univ. Min. Technol. 2015, 44, 24-28. [CrossRef]

7. Yu, B.; Chen, Z.; Yu, L. Water-resisting ability of cemented broken rocks. Int. J. Min. Sci. Technol. 2016, 26, 449-454. [CrossRef]

8. Li, J.; Xu, Y. Mechanical model of the collapse column water inrush prevention considering the confined water seepage and its application. J. China Univ. Min. Technol. 2016, 45, 217-224. [CrossRef]

9. Wang, B.; Liu, S.; Yang, Z.; Wang, Z.; Huang, L. Fine analysis on advanced detection of transient electromagnetic method. Int. J. Min. Sci. Technol. 2012, 22, 669-673. [CrossRef]

10. Xue, G.Q.; Cheng, J.L.; Zhou, N.N.; Chen, W.Y.; Li, H. Detection and monitoring of water-filled voids using transient electromagnetic method: A case study in Shanxi, China. Environ. Earth. Sci. 2013, 70, 2263-2270. [CrossRef]

11. Bauer-Gottwein, P.; Gondwe, B.N.; Christiansen, L.; Herckenrath, D.; Kgotlhang, L.; Zimmermann, S. Hydrogeophysical exploration of three-dimensional salinity anomalies with the time-domain electromagnetic method (TDEM). J. Hydrol. 2010, 380, 318-329. [CrossRef]

12. Trabelsi, F.; Ben Mammou, A.; Tarhouni, J.; Piga, C.; Ranieri, G. Delineation of saltwater intrusion zones using the time domain electromagnetic method: The Nabeul-Hammamet coastal aquifer case study (NE Tunisia). Hydrol. Process. 2013, 27, 2004-2020. [CrossRef]

13. Yu, C.T.; Liu, X.Y.; Liu, J.S.; Li, E.G.; Yue, P.; Yan, S.B. Application of Transient Electromagnetic Method for Investigating the Water-Enriched Mined-Out Area. Appl. Sci. 2018, 8, 1800. [CrossRef]

14. Danielsen, J.E.; Auken, E.; Jorgensen, F.; Sondergaard, V.; Sorensen, K.I. The application of the transient electromagnetic method in hydrogeophysical surveys. J. Appl. Geophys. 2003, 53, 181-198. [CrossRef]

15. Sharma, S.P.; Baranwal, V.C. Delineation of groundwater-bearing fracture zones in a hard rock area integrating very low frequency electromagnetic and resistivity data. J. Appl. Geophys. 2005, 57, 155-166. [CrossRef]

16. Simard, P.T.; Chesnaux, R.; Rouleau, A. Imaging Quaternary glacial deposits and basement topography using the transient electromagnetic method for modelling aquifer environments. J. Appl. Geophys. 2015, 119, 36-50. [CrossRef]

17. Rödder, A.; Tezkan, B. A 3D resistivity model derived from the transient electromagnetic data observed on the Araba fault, Jordan. J. Appl. Geophys. 2013, 88, 42-51. [CrossRef]

18. Peng, S.S.; Chiang, H.S. Longwall Mining; Wiley: New York, NY, USA, 1984; pp. 576-642, ISBN 978-0471868811.

19. Feng, X.W.; Zhang, N.; Chen, X.T.; Gong, L.Y.; Lv, C.X.; Guo, Y. Exploitation Contradictions Concerning Multi-Energy Resources among Coal, Gas, Oil, and Uranium: A Case Study in the Ordos Basin (Western North China Craton and Southern Side of Yinshan Mountains). Energies 2016, 9, 119. [CrossRef] 
20. Palchik, V. Formation of fractured zones in overburden due to longwall mining. Environ. Geol. 2003, 44, 28-38. [CrossRef]

21. Qian, M.G.; Shi, P.W.; Xu, J.L. Mining Pressure and Strata Control; China University of Mining \& Technology: Xuzhou, China, 2010; pp. 176-196, ISBN 9787564607968.

22. State Bureau of Coal Industry. Regulations of Buildings, Water, Rail Way and Main Well Lane Leaving Coal Pillar and Press Coal Mining; China Coal Industry Publishing House: Beijing, China, 2000; pp. 225-233, ISBN 9787502016623.

23. Zhang, D.; Zhang, W.; Ma, L.; Wang, X.; Fan, G. Developments and prospects of detecting mining-induced fractures in overlying strata by radon. J. China Univ. Min. Technol. 2016, 45, 1082-1097. [CrossRef]

24. Liu, C.; Xue, J.; Yu, G.; Cheng, X. Fractal characterization for the mining crack evolution process of overlying strata based on microseismic monitoring technology. Int. J. Min. Sci. Technol. 2016, 26, 295-299. [CrossRef]

25. Wei, J.; Wu, F.; Yin, H. Formation and height of the interconnected fractures zone after extraction of thick coal seams with weak overburden in western China. Mine Water Environ. 2017, 36, 59-66. [CrossRef]

26. Yang, H.Y.; Deng, J.Z.; Zhang, H.; Yue, J.H. Research on full-space apparent resistivity interpretation technique in mine transient electromagnetic method. Chin. J. Geophys. 2010, 53, 651-656. [CrossRef]

27. Spies, B.R. Depth of investigation in electromagnetic sounding methods. Geophysics 1989, 54, 872-888. [CrossRef]

28. Kong, X.Y. Advanced Mechanics of Fluids in Porous Media, 2nd ed.; University of Science and Technology of China: Hefei, China, 2010; pp. 41-52, ISBN 9787312021404.

29. Yang, T.; Chen, S.; Zhu, W.; Meng, Z.; Gao, Y. Water inrush mechanism in mines and nonlinear flow model for fractured rocks. Chin. J. Rock Mech. Eng. 2008, 27, 1411-1416. [CrossRef]

30. Shi, W.; Yang, T.; Yu, Q. A study of water-inrush mechanisms based on geo-mechanical analysis and an in-situ groundwater investigation in the Zhongguan Iron Mine, China. Mine Water Environ. 2017, 36, 409-417. [CrossRef]

31. Shi, B.Q.; Hou, Z.J. Mechanical analysis of fault activation water inrush in over burden rock and its application. Rock Soil Mech. 2011, 32, 3053-3057. [CrossRef]

32. Wang, G.; Wu, M.M.; Wang, R.; Xu, H.; Song, X. Height of the mining-induced fractured zone above a coal face. Eng. Geol. 2017, 216, 140-152. [CrossRef]

33. Kuroda, K.; Hayashi, T.; Do, A.T.; Canh, V.D.; Nga, T.T.V.; Funabiki, A.; Takizawa, S. Groundwater recharge in suburban areas of Hanoi, Vietnam: Effect of decreasing surface-water bodies and land-use change. Hydrogeol. J. 2017, 25, 727-742. [CrossRef]

34. Urrutia, J.; Jodar, J.; Medina, A.; Herrera, C.; Chong, G.; Urqueta, H.; Luque, J.A. Hydrogeology and sustainable future groundwater abstraction from the Agua Verde aquifer in the Atacama Desert, northern Chile. Hydrogeol. J. 2018, 26, 1989-2007. [CrossRef]

35. Yuan, R.Q.; Wang, S.Q.; Yang, L.H.; Liu, J.R.; Wang, P.; Song, X.F. Hydrologic processes of groundwater in a small monsoon-influenced mountainous watershed. Hydrol. Res. 2018, 49, 2016-2029. [CrossRef] 